УДК 711

\title{
Т.В. ВАВИЛОНСКАЯ
}

кандидат архитектуры, профессор, зав. кафедрой реконструкции и реставрации архитектурного наследия Самарский государственный архитектурно-строительный университет

\section{К.Н. МУШКАТ}

магистрант кафедры реконструкции и реставрации архитектурного наследия

Самарский государственный архитектурно-строительный университет

\section{АНАЯИЗ РЕТРОСПЕКТИВЫ РАЗВИТИЯ СОЦИАЯЬНО-ДОСТУПНОГО ЖИЛЬЯ} THE RETROSPECTIVE ANALYSES OF SOCIAL AFFORDABLE HOUSING DEVELOPMENT

Рассматриваются проблемь развития соичильнодоступного жилья на примере российского и зарубежноzo onblma.

Ключевье слова: социильно-доступное жилье, многоквартирные дома, социальные нормыл.

В развитых странах проблемы социального жилья уже более ста лет решаются раздичными способами, но суть подхода в предоставлении жииья малообеспеченным и незащищенным категориям граждан.

Один из первых многоквартирных социальных домов (рис. 4) появился в середине XIX в. в Париже. В нем было 194 квартиры на 500 человек. Затем подобные сооружения стали возводиться и в других странах.

Массовоестроительствосоциально-доступных домов началось в Северной Америке и Западной Европе после первой мировой войны. Это были здания от 3 до 6 этажей из дешевых материалов для рабочих и их семей с низкой платой за аренду и коммунальные услуги. Особенно энергичными темпами социальное строительство развернулось в Германии и Испании. В Германии такие дома возводились на окраинах больших городов, где по замыслу проектировщиков трудящиеся получали в изобилии “дихт, люфт унд зонне” - свет, воздух и солнце.

После второй мировой войны создание доступного жилья по приемлемым ценам стало приоритетным направлением государственной политики всех развитых стран. Настоящий строительный бум социального жилья начался в Британии. Первоначально приоритет отдавался возведению поселков с домами, в которых могла проживать одна, но чаще несколько семей. На каждую семью в среднем приходидось приблизительно 36-40 м²
The problems of social affordable housing development in Russia and abroad are considered in this article.

Key words: social affordable housing, blocks of flats, social standards.

жилой площади. Внутри дома в каждой квартире (у каждой семьи) были ванная комната и туалет, что для простых людей было в те годы настоящим чудом.

Но поскольку потребность в социальнодоступном жидье постоянно росла, уже в 1950-е гг. на смену невысоким домам стади приходить дома-башни. Считалось, что высотки позволяют обеспечить жильем гораздо большее количество нуждающихся и значительно быстрее. Однако уже в конце 1960-х гг. общество разочаровалось в башнях и их строительство затормозилось.

Правительством была сделана ставка на приобретение малообеспеченными гражданами новых квартир/домов в собственность. Одновременно обитатели уже существующих социальных домов получили возможность выкупить свое жилье на выгодных условиях: для домов предлагалась скидка до 60 \%, для квартир - до 70 \% от рыночной стоимости.

В качестве удачного примера выполнения социальных проектов стоит привести Швецию. Здесь с 1964 по 1974 гг. выполнялась государственная программа “Милдион”, по которой для малообеспеченных семей быстрыми темпами было возведено более 1 млн единиц довольно приличного жилья.

Со временем социальные дома почти повсеместно стали превращаться в жилье для тех слоев населения, которые не могли самостоятельно обзавестись крышей над головой, а также для беженцев 
и иммигрантов. А высота подобных сооружений в последние десятилетия достигла 15-30 этажей.

Как правило, социальное жилье принадлежит центральным или местным властям, а также разного рода структурам, которые контродирует государство. В разных странах понятие “социальнодоступное жилье” трактуется по-разному. Его еще называют общественным, государственным, муниципадьным, типовым и доступным. Так, CECODHAS (организация, занимающаяся в Европейском Союзе жилищными проблемами) определяет социальное жилье как широкодоступное и придичное жилье для широких слоев населения.

Каждое государство устанавдивает собственные стандарты социадьного жидья в соответствии с историко-культурными традициями и экономическими возможностями. В большинстве стран Европейского Союза размер жилой комнаты на одного человека не может быть меньше $4 \mathrm{~m}^{2}$, а в Германии - не менее 8 м $^{2}$ при высоте потолка не менее 2 м. Размеры и удобства социального жилья сильно от-
Аичаются от страны к стране, а порой и от города к городу. В государствах с высоким качеством жилой недвижимости, например в Германии, Швеции, Австрии и Голландии, соответственно и социальное жилье довольно приличное.

В настоящее время социально-доступное жилье широко известно во многих странах, включая Индию, Китай, Австралию и Новую Зеландию, огромное внимание уделяют социальному жилью в Северной Америке и Западной Европе.

В странах Западной Европы на социальные жилищные проекты расходуется от 0,1-0,3 \% ВВП (Италия, Греция) до 1,2-1,4% ВВП (Финляндия, Дания, Австрия). Во Франции этот показатель составляет 1,9 \% ВВП (рис. 1).

По доле в структуре недвижимости в странах Европейского союза (ЕС) больше всего социальнодоступных домов построено в Голландии - почти треть от всего жилого фонда. Далее следуют Австрия, Дания, Британия, Франция, Финдяндия и Швеция - 19-23 \% от всего фонда (рис. 2).

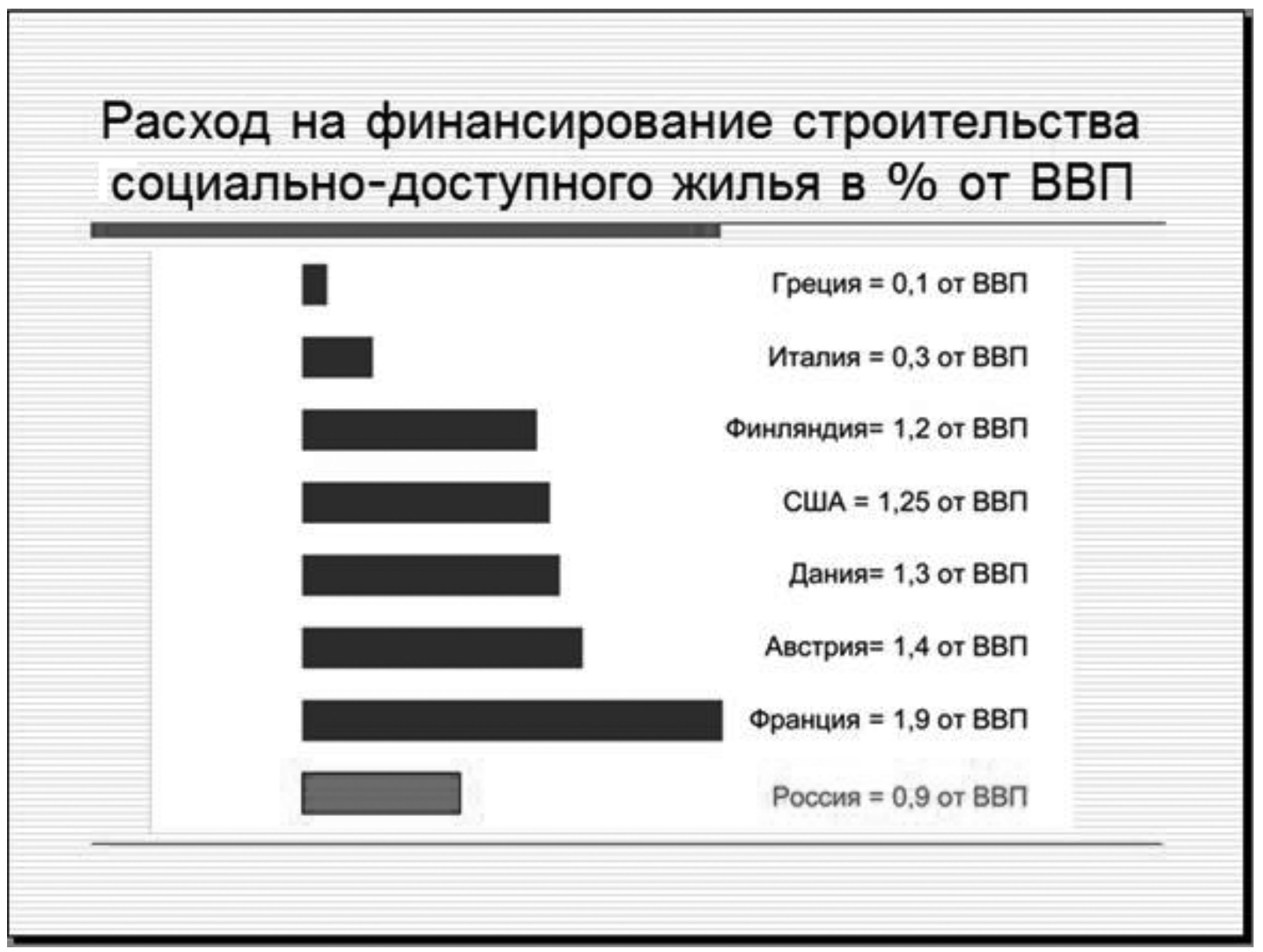

Рис. 1 




Рис. 2

В Бельгии и Германии его доля незначительна - менее 7 \%. В Дании, Франции и Британии бояее четверти всех семей проживают в социальных домах, т. е. тем или иным путем дюди получают государственную поддержку при аренде жилья и оплате жилищно-коммунальных услуг (рис. 3).

В странах ЕС для финансирования социальных проектов привлекаются деньги из разных источников: финансовые средства центральных, региональных и местных властей, частные инвестиции, пожертвования. Последние тенденции явно говорят о том, что центральные власти постепенно уходят от решения проблем социального жилья, делегируя принятие решений на местный уровень.

В Швеции, например, расходы на социальное жилье (снос старых домов, возведение новых, реконструкция, ремонт, обслуживание) делятся между центральным правительством и муниципадитетами поровну. Чаще всего гражданам на дьготных условиях предоставляются в социадьный наем квартиры, но в ряде стран активно разраба- тываются и совершенствуются схемы, по которым малообеспеченным выдаются субсидии на приобретение собственных домов или квартир. Для этого во многих странах (Франция, Голландия, Греция, Дания, Бельгия, Испания, Ирландия, Британия) приняты разного рода нормативные документы, делающие ипотечную ссуду доступной. Это могут быть пониженные процентные ставки, прямые субсидии и налоговые скидки. А чтобы средние и мелкие инвесторы могли без опаски покупать социальные ипотечные бумаги, государство обязуется погашать долги в случае дефолта заемщика, как говорится, при любой погоде. Поэтому, хотя срок погашения социальной ипотечной ссуды может превышать 30 лет, государственное поручительство сводит риски кредитора к минимуму. В качестве подстраховки часто действуют совместные частно-государственные фонды.

Проблемы социального жияья везде решаются по-разному. К примеру, в Дании этим занимаются жилищные коммерческие организации, которые получают за это определенные налоговые 
Процентное соотношение людей, проживающих в СДЖ, от общей численности населения

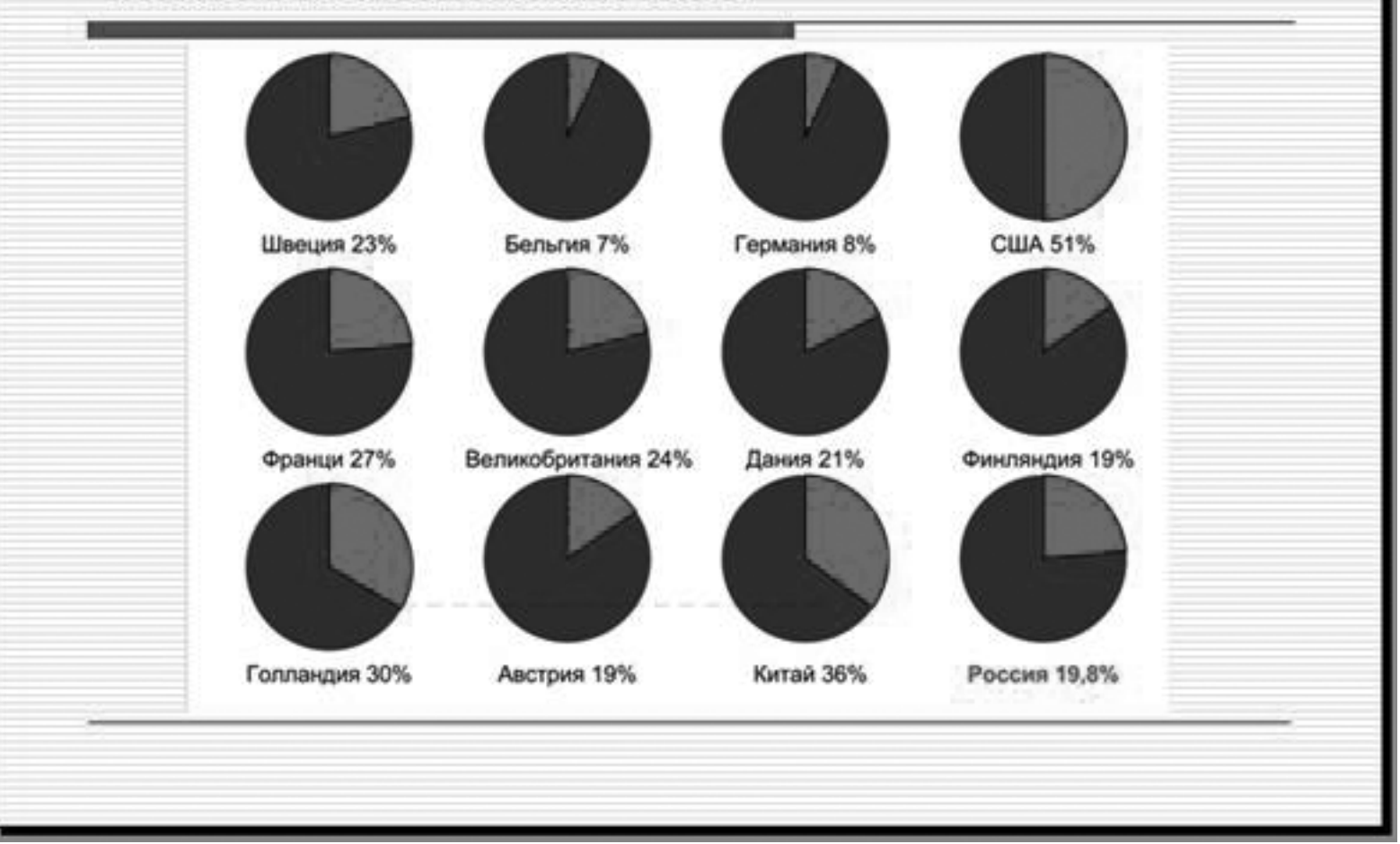

Рис. 3

иьготы и субсидии. Во Франции - частные компании, контродируемые муниципадитетами, в Голландии - жилищные ассоциации, чаще всего частные, в Австрии - компании, собственниками которых являются местные или центральные власти, профсоюзы, банки и прочие структуры.

В Британии социально-доступные дома находятся в компетенции местных властей и жилищных ассоциаций. Жидищные ассоциации готовят регулярные отчеты по своей работе, которая должна быть эффективной и прозрачной. Самый большой социальный район страны расположен в Лондоне, в нем проживают 100 тыс. человек.

В Британии практикуется и смешанное расселение, чтобы искдючить социадьную сегрегацию. Для этого при возведении коммерческого жилья застройщик по договору обязуется предоставить часть готовых жилых площадей муниципадитету для расселения малообеспеченных семей.

Довольно часто социально-доступное жидье возводится на договорных условиях частными компаниями по заказу государственных или полу- государственных структур. Считается, что это стимулирует конкуренцию. Возведение и содержание социальных домов сопряжено для частных инвесторов и застройщиков с рисками, поэтому сфера социального жилья поддерживается государственными субсидиями, грантами, гарантиями и налоговыми иьготами.

Во многих развитых странах, чтобы снизить конечную стоимость жилья, девелоперам предоставляются налоговые скидки, а земля, выделяемая под социальные застройки, продается строительным компаниям по ценам ниже рыночных.

Для стимулирования рынка социально-доступного жилья принимаются раздичные меры. Так, во Франции по действующему законодательству при каждой компдексной застройке как минимум 20 \% жилья должно выделяться малообеспеченным гражданам, а в Италии в этих целях отменен налог на строительство новых домов.

В США социальное домостроительство стало бурно развиваться в середине XX в. Первоначально социально-доступные дома строились как жилье с 
повышенными удобствами для рабочих и представителей среднего класса, они были альтернативой ветхим кварталам и трущобам.

В 1974 г. конгресс США принял жилищную программу, которая стимулировала возведение частными компаниями социально-доступного жилья. По этой программе малообеспеченные граждане получали ежемесячную субсидию (деньги перечислялись владельцам жилья) в качестве компенсации за аренду, когда она превышала $30 \%$ от их доходов. В дальнейшем в США начали осуществляться проекты, направленные на снижение преступности в социальных районах. Одновременно во многих городах США с середины 1990-х гг. начали строиться кварталы смешанного заселения.

По данным министерства жилищной поиитики и развития городов США, около 1,3 млн. американских квартиросъемщиков проживает в общественных домах, управдяют которыми 3300 жилищных ассоциаций. Большая часть общественных домов принадлежит непосредственно властям, остальная - коммерческим структурам на договорной основе. Министерство распределяет и координирует федеральную помощь социальным домам, оказывает профессиональную помощь в их планировании и развитии.

В России архитектура социадьного жилища практически не изменилась с момента выхода первого СНиПа индустриальной эпохи «Жилые здания» [2], который нес в себе нормы серединыконца 1920-х гг. Иными словами, в современном мире используются критерии качества, сформулированные около столетия назад.

Массовость в нашей стране социальное жильё приобрело в середине XIX в. как цивилизационный ответ на условия, в которых проживали наиболее слабые и незащищенные слои общества.

В 30-е гг. постепенно приходит сталинская классика. Массовое жилье в это время было в основном 2-4-этажным. Строительство домов в городе велось, как правило, по разработанным типовым проектам традиционными, ручными методами возведения. Тяжелое экономическое поиожение, особенно в военное время, ограничивало применение новых материалов и прогрессивных технологий.

Качество этих построек очень разное, стены могли быть как кирпичные, так и блочные или деревянные дибо каркасно-засыпные; фасады штукатурились. Как правило, это были рабочие жилые поселки. Планировочную структуру кварталов с данной застройкой отличает комплексное решение и высокое качество градостроительного проекта. Несмотря на трудное время, строительство велось планомерно и осмысленно. Планировка была регулярной и рациональной: за счет расположения домов по периметру квартала создавалось закрытое пространство, разбитое внутриквартадьными домами на уютные дворики (рис. 4).

Смена идеологии во второй половине 30-х гг. легитимировала появление монументальных жидых ансамблей в центре города. Данная типология, появившаяся в сталинские времена, так и называется - «сталинки». Это добротные кирпичные здания с метровыми стенами, высокими потолками и впечатляющими метражами комнат, т.е. весьма дорогое и качественное жилье, располагающееся в центре города. Идея равенства первых послереволюционных лет сменяется идеей утверждения власти. В 30-е гг. все жилье становится ведомственным, и если малоэтажное жилье реализовывается радом с заводами и фабриками, формируя рабочие поселки, то жилье для новой элиты располагается на главных площадях и улицах.

Архитектура сталинской классики богата пластикой фасада и отличается парадностью. Многие из зданий этого периода явдяются памятниками истории и архитектуры. Данный тип жилья до сих пор является достаточно дорогим, у многих горожан он до сих пор вызывает ощущение надежности, стабильности. Основной минус - отсутствие регулярного ремонта таких зданий и замены инженерных коммуникаций. Сталинская застройка формировала периметры кварталов и нередко являлась частью больших градостроительных ансамблей. Следование красным диниям кварталов было не обязательным на протяжении квартала или даже одного дома (Комсомодьский проспект), для избегания монотонности уличный фасад разбивался углубленными зелеными партерами либо смещением зданий в глубь квартала. Многие из кварталов достраивались позднее «хрущевками», во внутреннем пространстве кварталов размещалось еще несколько зданий, разбивая пространство на более интимные дворики (рис. 5).

«Воспроизводство жилья неизбежно связано с развитием форм жилья»[1], а значит и с изменением критериев оценки его качества. Архитекторы, занятые в сфере его проектирования, ищут новые пути решения, принимают новые стандарты 


\section{СДЖ различных стран}

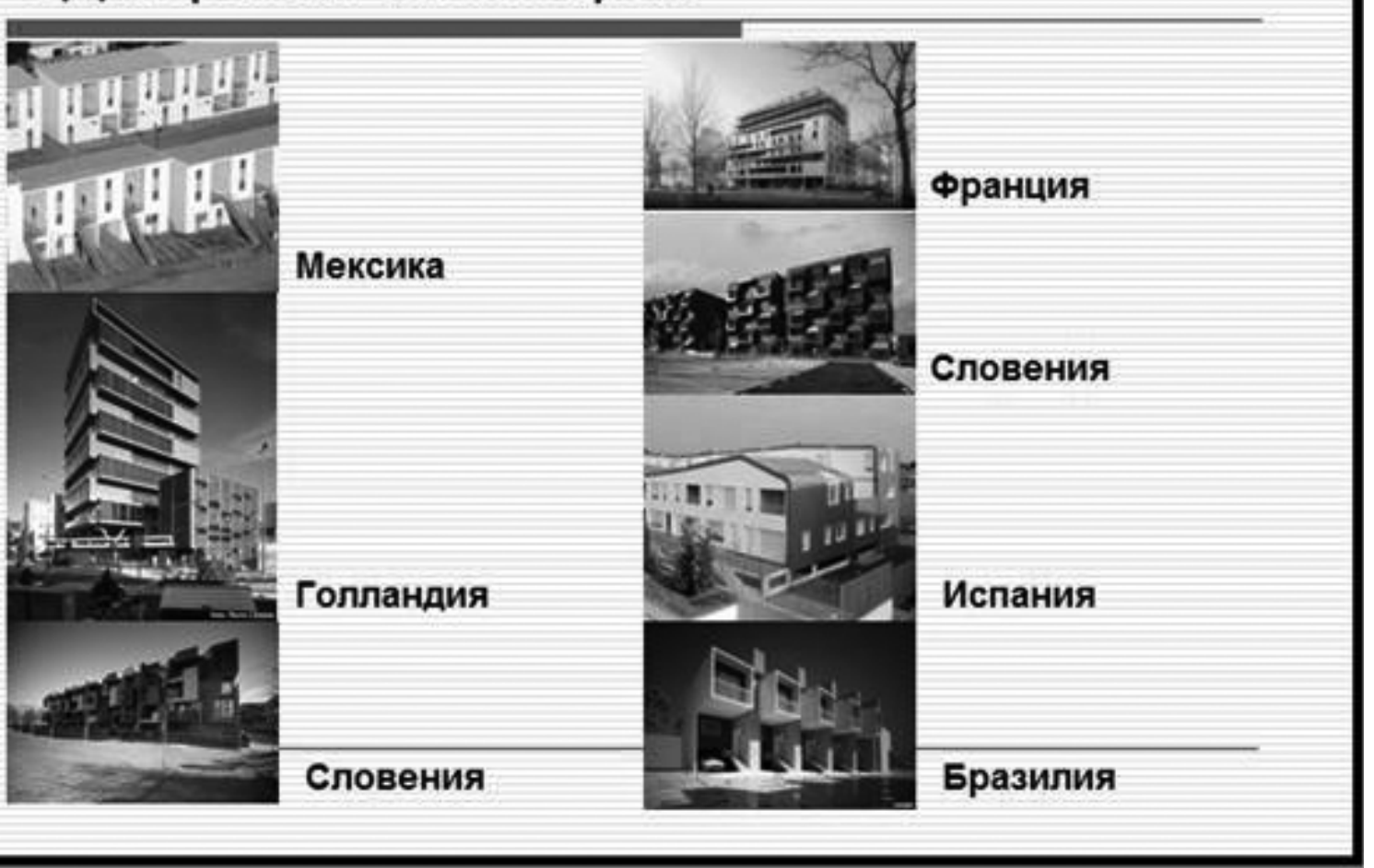

Рис. 4

проектирования. Происходит возвращение и переосмысление более ранних моделей. Эта динамика делает сферу проектирования социального жилища интересной с профессиональной точки зрения. Повышается качество среды, а значит и уровень жизни населения.

Эра типового жилья наступила, как и в Европе, в послевоенный период. Это был период восстановления страны и решения проблемы дефицита жииья в городах. Жилье строилось в рекордные сроки, что, естественно, не могло не сказаться на качестве постройки. Также сыграли свою роль и заниженные требования к жилью. Пятиэтажные панельные и кирпичные «хрущевки» обладают многими недостатками: односторонняя ориентация, неудобная планировка, очень маленькие коридор, кухня и санузел; в панельных домах, кроме этого, плохая тепио- и звукоизоляция.

Панельное домостроение в этот период стало главным направлением жилищного строительства. Широко применялись разработанные типовые 4-6-квартирные секции. Все типовые панельные дома имеют всего несколько вариантов планировок, квартиры и дома похожи друг на друга как близнецы. Тотальная типизация 70-х гг. пагубно отразилась на облике многих жилых районов города.

Принцип застройки кварталами мешал реализации теории ступенчатого обслуживания населения: комплексно и равномерно размещать необходимые учреждения обслуживания - школы, детские сады, магазины, столовые, спортивные сооружения, кинотеатры и клубы, согласно схеме радиальной доступности и значения объекта в системе.

Так появились бескрайние спальные микрорайоны, сформированные типовыми, как правиио, панельными многоэтажками, называемыми «брежневки». Первые «брежневки» - это улучшенный вариант «хрущевок», в этот период дома строились уже 9-этажными и имеди чуть большие площади, в домах были лифт и мусоропровод. Первые 


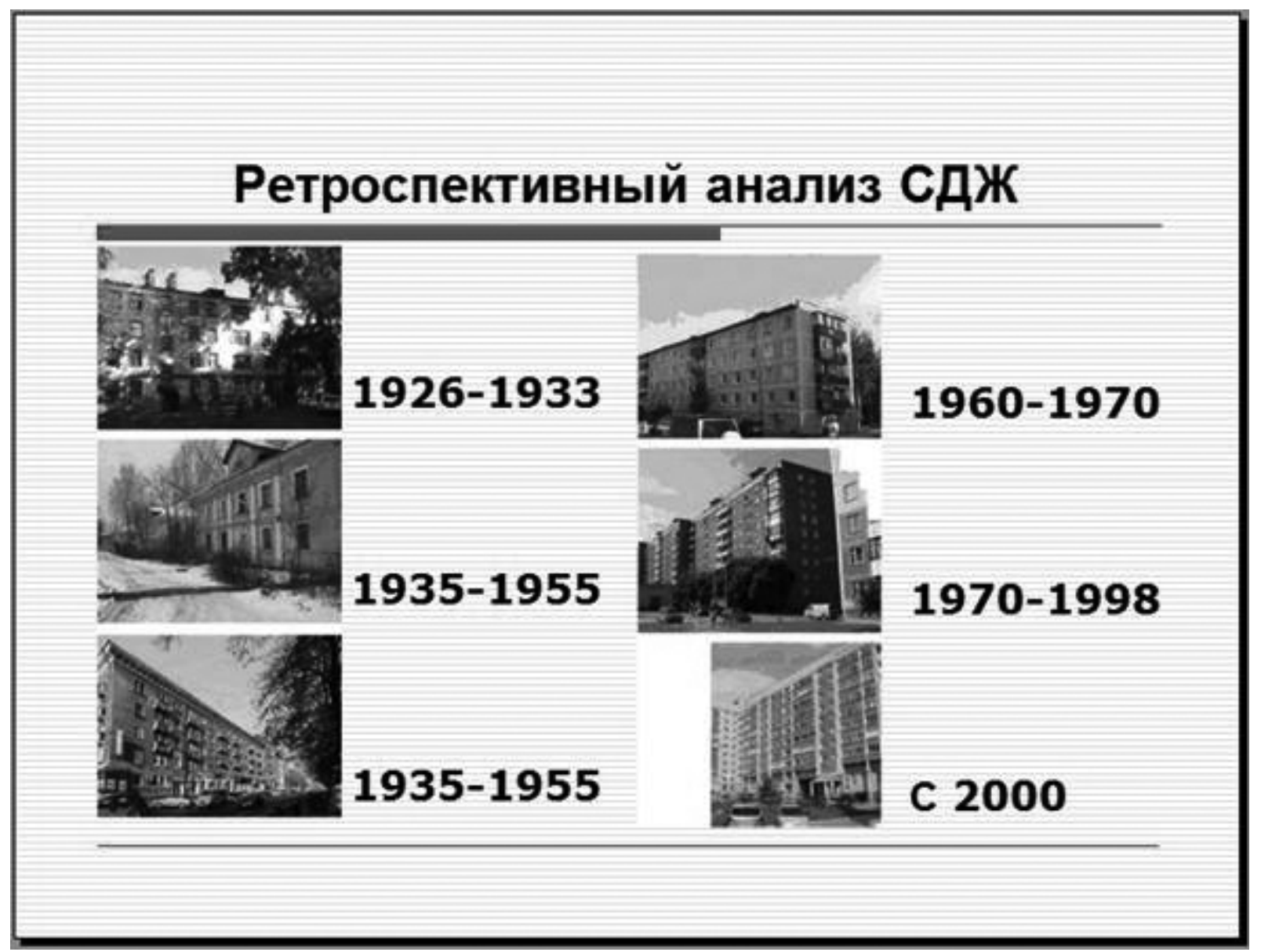

Рис. 5

9-этажные дома реализовывались с плотностью 5500-6000 м²/га, директивная плотность позднее: не ниже 7500 м²/га. Жилые дома данной группы можно разделить на две категории: дома, построенные по типовым и по индивидуадьным проектам. Последние стали реализовываться в 80-е гг.

Планировка застройки стала в какой-то момент настолько «свободной», что здания ставились без определенной закономерности, просто заполняя свободные места в застройке. В застройке этого периода характерно расположение зданий без учета пространственной композиции и разделения пространства на общественное и частное (коллективное), со слабым намеком на дворы.

Дворы пространственно были не сформированы, расстояния между зданиями в силу высокой этажности очень большие, результатом чего явилось огромное количество «ничейных» территорий. Усугубляют проблему такого жилья и средовое восприятие зданий - однотипные монотонные фасады большой протяженности, стихийное решение парковок и недостаток уютной дворовой среды с местами для отдыха, прогуяок, детскими игровыми площадками. Автомобилизация также плохо отразилась на зонировании в жилых дворах города вообще, а в особенности в районах с многоквартирными жилыми домами. Скудное озеленение (недостаток деревьев) и неухоженные газоны и дорожки доподняют безрадостную картину.

Доминирующей типологией и по сей день остается многоквартирный дом, хотя за последние годы появились типологически другие дома: загородные коттеджи, маленькая группа сблокированных домов.

В целом, за небольшим исключением, можно сказать, что ничего не изменилось по сравнению с эпохой социадизма: ни качество зданий, ни качество окружающей среды.

Однако все это не мешает российским социальным нормам оставаться одними из самых высоких в мире. В соответствии с Жидищным кодексом РФ при вселении семьи в отдельную квартиру го- 
сударственного жилого фонда ей предоставдяется

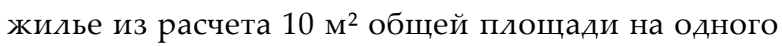
взрослого человека.

\section{БИБЯИОГРАФИЧЕСКИЙ СПИСОК}

1. Кутузов, В.В. Воспроизводство жилья в условиях социально-ориентированной рыночной экономики: Основные положения. Комментарии [Текст] / В.В. Кутузов. - М. : ЦНИИЭПжилища, 1994. - 290 с.

2. Овсянников, В.А. Жилая среда и социальные проблемы жилища [Электронный ресурс] / В.А. Овсян- ников В.А. - Режим доступа: http://domowed.narod.ru/ star_stat-1.htm

3. Кияненко, К.В. Социальное видение в современной англо-американской архитектуре [Текст] / К.В. Кияненко //Архитектурный Вестник. - 2004. - №3. - C. 84-86.

4. Доктрина жизнеобустройства среднего класса России [Электронный ресурс]. - Режим доступа: http:// www.inop.ru/files/doktrina_27_05_08.doc

() Вавидонская Т.В., Мушкат К.Н., 2011 